\title{
Risedronate as a therapeutic trial post-hysterectomy in premenopausal women to prevent osteoporosis
}

\author{
Ban Hadi Hameed-F.I.C.O.G ${ }^{*}$, Ahmed sabeeh abid ali - F.I.C.M.S. ${ }^{*}$, Hala Abdul Ghani Zgayer -F.I.C.O.G. ${ }^{* *}$
}

\begin{abstract}
Background: Osteoporosis is a skeletal defect manifested by a reduction of bone strength as a result of reduced bone mass to the extent that there is a higher risk of fracture even on minor trauma. Hysterectomy in a premenopausal woman is a well known cause of ovarian failure resulting in an increased risk of osteoporosis.

Objective : To clarify bisphosphonate's preventive effect on osteopenia and osteoporosis in premenopausal women after hysterectomy.

Type of the study: Cross -sectional study.

Method: 84 premenopausal females post hysterectomy aged between 40 - 50 years, were enrolled in this randomized controlled double blinded trail at $\mathrm{Al}$ Yarmouk teaching hospital and private clinic in Baghdad for a period of two years from Augest 2011 till July 2013. Participants were assigned as: $1^{\text {st }}$ group (study group 42 women): received risedronate treatment "over a period of one year" with calcium and vitamin D; and $2^{\text {nd }}$ group (control group 42 women) were taken as a matched group for:"age, body mass index (BMI) and fracture history", received only calcium and vitamin $\mathrm{D}$ as a placebo. Bone density had
\end{abstract}

been assayed at the end of the year for all participants and evaluated for osteopenia and osteoporosis.

Results:_Osteopenia and osteoporosis were significantly lower in the risedronate arm as compared to those not received the drug $" 14.3 \% \& 11.9 \%$ versus $26.1 \% \& 19 \%$ respectively".

Conclusion: The bone mineral density results were significantly better in those who received risedronate than those not received the drug.

Key words: Osteoporosis, hysterectomy, Risedronate

\section{Al-Kindy College Medical Journal 2018: Vol.14 No.1 Page: 4-7}

\author{
${ }^{*}$ AL-Mustansyria/ Medical College \\ ${ }^{* *}$ Al Nahrain university/ Medical college \\ ${ }^{* * *}$ AL-Mustansyria/ Medical College
}

Received $4^{\text {th }}$ July 2016, accepted in final 17 $7^{\text {th }}$ Oct 2017 Corresponding to Ban Hadi Hameed-F.I.C.O.G

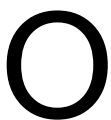

steoporosis is a defect of the bone architecture which results in an altered strength and quality of skeleton so that the individual is subjected to a higher risk of fracture, with its considerable influence on the individual life in form of hospitalization and mobility difficulties while osteopenia describes a bone density that is sub-normal but not as low as osteoporosis with a lower risk of fracture ${ }^{(1)}$. Females are at more risk than males as there is a fifty percent reduction of bone mass when they approach seventy years old, there is also a height loss with aging resulting from vertebral cracks and a reduced space of inter_vertebral disc from collagen loss ${ }^{(2)}$. According to the report of Bone Health and Osteoporosis "A Report of the General Surgeon 2004" this problem has a major life effect and it is the most prevalent bone defect ${ }^{(3)}$. It is a preventable health problem as there are a lot of therapies that are effective with minimal side effects, However, in spite of that only a few percent of patients with a fracture history received a bone scan or treatment for osteoporosis following the fracture ${ }^{(4)}$. As hysterectomy is a common surgery in young age women, many studies evaluated its consequences and one of its drawbacks is the ovarian failure that may occur years before its natural time ${ }^{(5,6,7)}$. Due to the definite risk of osteoporosis in early menopause, we evaluated the effect of bisphosphonates in this clinical trial to prevent accelerated bone loss. Risedronate sodium is approved by the FDA for the prevention and treatment of postmenopausal osteoporosis ${ }^{(8)}$. The fracture hazard is markedly lowered after therapy for one year in those with a prior fracture ${ }^{(9)}$. Others recommend treatment with bisphosphonates for women at high risk of fracture ${ }^{(10,11)}$. Various doses had been studied; However $5 \mathrm{mg}$ risedronate per day resulted in the same bone density (BMD) results as $35 \mathrm{mg}$ per week in osteoporotic women ${ }^{(12)}$. Owing to the increasing rate of caesarean section in our country, more cases with caesarean hysterectomy are seen in younger age group which indicates prophylactic measures to prevent bone mass deterioration.

Study objective_: To clarify bisphosphonate's preventive effect on osteopenia and osteoporosis in premenopausal women after hysterectomy.

Method: A randomized controlled double blinded clinical trial was extended for two years from August 2011 till July 2013, women attended Al Yarmouk hospital and a private clinic for any gynecological complaint and fulfill the inclusion criteria were enrolled in this work in conjunction with the orthopedic surgeon for initial evaluation and involvement in the study. The study was approved by ethical committee of AL-Yarmouk teaching hospital and AL- Mustansyria medical college in Baghdad. After accepting participation with consent from all candidates, women included in this study were premenopausal (40-50 years old) and had hysterectomy with ovarian preservation (the main indications for hysterectomy were abnormal uterine bleeding and placenta accreta).

Exclusion criteria: Bisphosphonate's allergy, hypocalcemia, renal failure, patients with medical diseases that increase the risk of osteoporosis as thyroid disease and hyperparathyroidism, alcohol intake, smoking, thin women, those taking steroids and hormone replacement therapy. 
Initial clinical evaluation with estimation of body mass index $\left[\mathrm{BMl}=\mathrm{wt}(\mathrm{kg}) / \mathrm{ht}\left(\mathrm{m}^{2}\right)\right]$. the candidates were subjected to a double blinded study "as the pharmacist prepared the treatment to be given for each group in labeled envelops" with a computer based randomization into: study group received calcium "1000 mg" and vitamin D "400 IU" orally daily with risedronate treatment (35 mg orally weekly) for a period of one year and control group received calcium "1000 mg" and vitamin D "400 IU" orally daily, taken as a matched group for age, $\mathrm{BMI}$ and fracture history. BMD was measured after completing the treatment in the lumbar spine and the femur by dual-energy X-ray absorptiometry (DEXA) at Al Yarmouk hospital and according to the diagnostic criteria proposed by the World Health Organization (WHO) in 1994: up to $-1.0 \mathrm{SD}$ normal, from -1.1 to -2.49 SD osteopenia, and below -2.5 SD osteoporosis (13) Statistical analysis: Statistical analysis was performed using SPSS-22 (Statistical Packages for Social Sciences Version 22) 2013 analytic software. The values were expressed as mean and standard deviation. The significance of difference in means was tested by the student t- test for two independent means where as the significance of difference between proportions had been tested using the Pearson chisquare test. A P value of less than 0.05 was considered as significant.

Results: From ninety women involved in the study, 84 women completed the follow up, three had been excluded due to medical diseases ( 2 cases with thyroid disease and 1 case with malabsorption) and three were lost in the follow up. Those women assigned into: study group 42 women and control group 42 women, taken as a matched group for age, BMl and fracture history as shown in table 1 below. Table 2 clarifies the significant difference between the groups with regard to osteopenia, osteoporosis and fracture number. 11 (26.1\%) patients in the control group had osteopenia while in the study group $6(14.3 \%)$ patients had osteopenia after one year treatment with risedronate, concerning osteoporosis $8(19 \%)$ patients in the control group versus 5 (11.9\%) patients in the study group had osteoporosis. The fracture number in the study group was $2(4.8 \%)$ compared to $5(11.9 \%)$ in the control group. The percent of osteopenia and osteoporosis was significantly lower in those received the drug compared to those not received the drug as shown in figure 1 below: Concerning side effects of risedronate, we had two cases with heart burn and vomiting that resolved after stoppage of the drug and re-consumed after resolution of symptoms.

Table 1: The demographic data of the participants. Data was expressed as

" mean \pm SD" $n=42$ for both groups.

\begin{tabular}{|c|c|c|}
\hline Criteria & Control group & Study group \\
\hline Age (years) & $44.3 \pm 3.04$ & $44.25 \pm 5.06$ \\
\hline $40-44$ & 32 & 30 \\
\hline $45-50$ & 10 & 12 \\
\hline $\mathrm{BMI}\left(\mathrm{Kg} / \mathrm{m}^{2}\right)$ & $25.86 \pm 1.48$ & $\mathbf{2 5 . 4 5 \pm 1 . 4 7}$ \\
& & \\
\hline $19-24.9$ & 22 & 21 \\
\hline $25-30$ & 20 & 21 \\
\hline Fracture & 3 & 3 \\
\hline
\end{tabular}

history

Table 2: The response to risedronate as assessed by BMD measurement and fracture number.

\begin{tabular}{|c|c|c|c|c|}
\hline Criteria & & $\begin{array}{l}\text { Control } \\
\text { group }(42 \\
) \\
\text { No. of } \\
\text { patients ( } \\
\% \text { ) }\end{array}$ & $\begin{array}{l}\text { Study } \\
\text { group(42 } \\
\text { ) } \\
\text { No of } \\
\text { patients( } \\
\% \text { ) }\end{array}$ & $\begin{array}{l}P \\
\text { value }\end{array}$ \\
\hline \multirow[t]{3}{*}{ BMD } & $\begin{array}{l}\text { Up to }-1.0 \\
\text { SD } \\
\text { ( Normal) }\end{array}$ & $23(54.7)$ & $31(73.8)$ & \multirow[t]{3}{*}{$\begin{array}{l}\mathbf{0 . 0 0 0 1} \\
*\end{array}$} \\
\hline & $\begin{array}{l}\text { From }-1.1 \text { to } \\
-2.49 \mathrm{SD} \\
\text { (Osteopenia) }\end{array}$ & $11(26.1)$ & $6(14.3)$ & \\
\hline & $\begin{array}{l}\text { Below }-2.5 \\
\text { SD } \\
\text { (Osteoporosi } \\
\text { s) }\end{array}$ & $8(19)$ & $5(11.9)$ & \\
\hline $\begin{array}{l}\text { Fractur } \\
\text { e } \\
\text { number } \\
\text { (from } \\
\text { the total } \\
\text { in each } \\
\text { group) }\end{array}$ & $\begin{array}{l}\text { (femoral, } \\
\text { hip, lumbar } \\
\text { and radial } \\
\text { bones } \\
\text { fractures) }\end{array}$ & $5(11.9)$ & $2(4.8)$ & $\begin{array}{l}\mathbf{0 . 0 1 7 *} \\
*\end{array}$ \\
\hline
\end{tabular}

* The significance of difference between proportions was tested by the Pearson chi-square test.

**The significance of difference in means was tested by the student t- test for two independent means

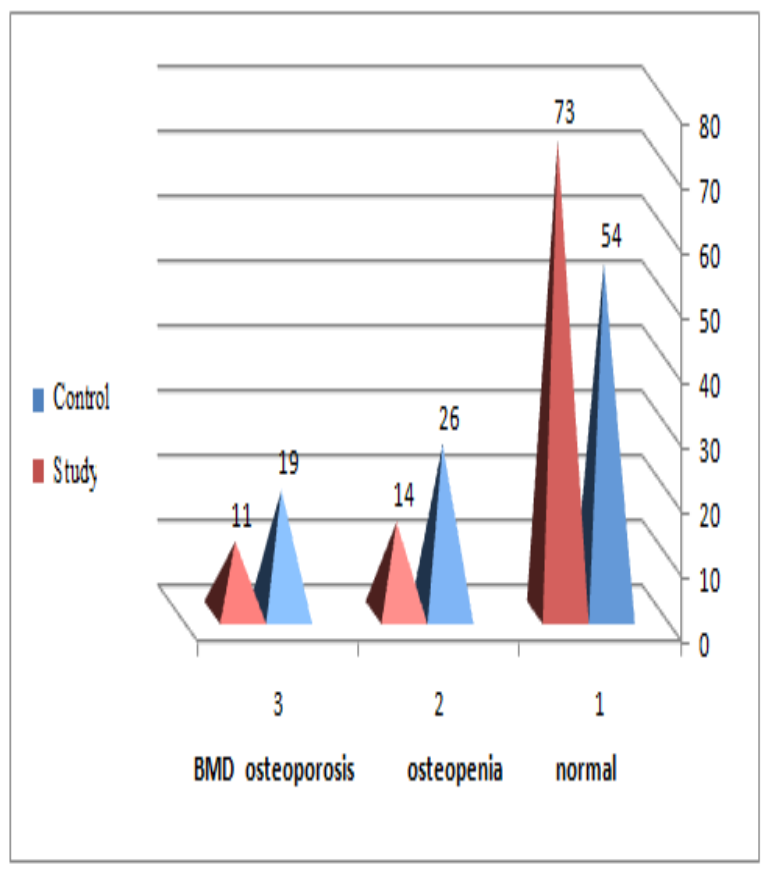

Figure 1: Percentages of osteopenia and osteoporosis in the study and control group. 
Figure 2 below showed an example of osteopenia result in one of our patients

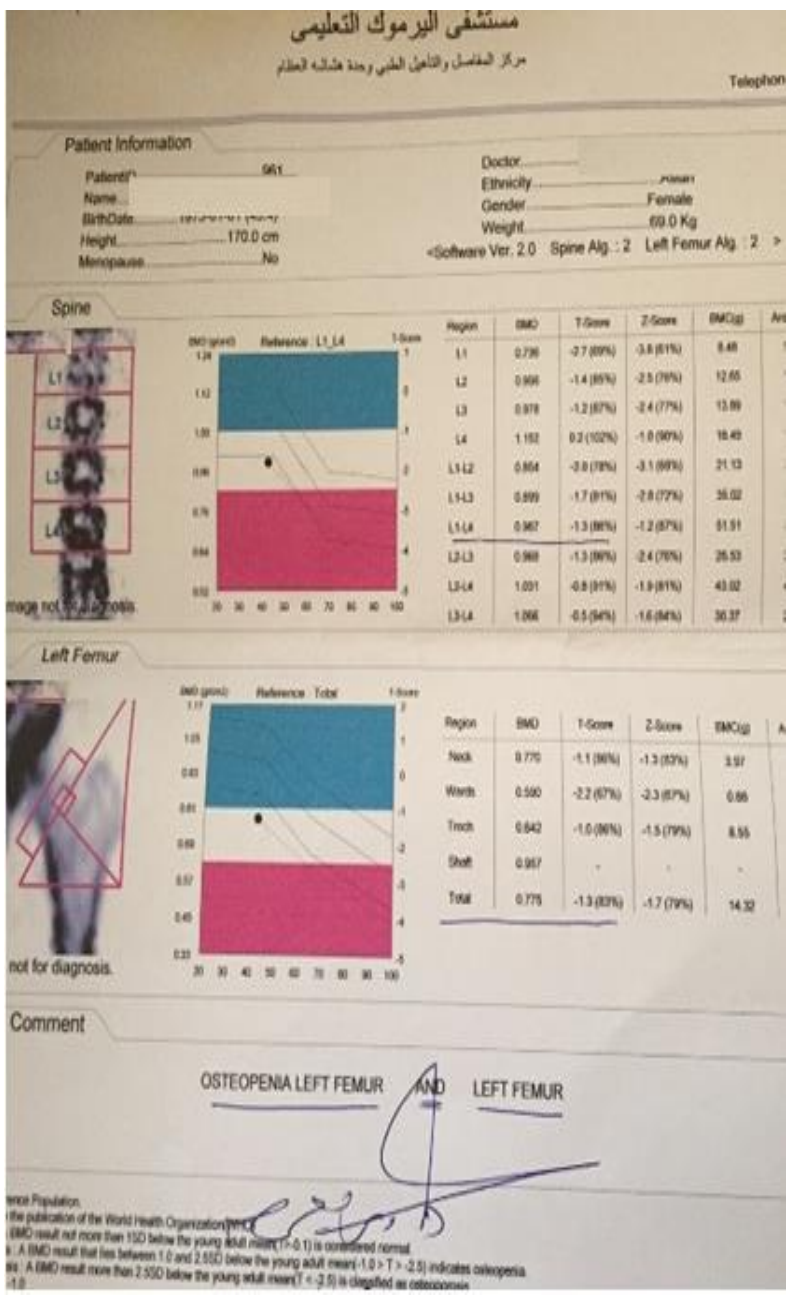

Figure 2: patient had osteopenia

Discussion: Osteoporosis is an important health issue which has social, medical and economic effects. Women after menopause have major changes in bone composition which compromise bone strength and predispose to fractures ${ }^{(14)}$. Hysterectomy is the most frequent gynecological surgery in america ${ }^{(15)}$. There is a concern whether uterine removal is a risk for early menopause, some studies showed that ovarian function was adversely affected post-hysterectomy $(5,6,16,17)$. Ovarian function assessment by hormonal analysis after uterine removal in contrast to women with an intact uterus revealed that menopause occurs earlier in women post-hysterectomy ${ }^{(7)}$. Increasing woman age, low BMI and fracture history were significant risk factors for osteoporosis ${ }^{(18,19)}$ In this clinical trial we studied a matched group for age, BMl and fracture history to eliminate the effect of these variables. We used risedronate as a prophylactic treatment in women posthysterectomy as it is a first line therapy in postmenopausal osteoporosis ,Grade A_guidelines ${ }^{(20)}$. Regarding Bisphosphonates choice, both risedronate and alendronate have a potent preventive influence on bone loss in women after menopause in the femur and spines whether having osteoporosis or not ${ }^{(20)}$. We took risedronate as gastrointestinal endoscopy found a reduced incidence of ulcerations with its use compared to alendronate ${ }^{(21)}$. In this clinical trial osteopenia and osteoporosis were significantly lower in the study group after 1 year of risedronate compared to control and this in agreement with a study of the effect of risedronate 5 mg per day, which found that the bone density was better in the femur and spines compared to women taking placebo for 2 years ${ }^{(22)}$. In other study which evaluated its preventive action, the bone density at the lumbar spine and trochanter increased by 5.7 and $5.4 \%$ compared to no treatment ${ }^{(23)}$.

Concerning fracture risk, we had 5 cases with fractures affecting the femoral, hip, lumbar and radial bones in the control group while in the study group only two cases had fractures and this appears to be due to the effect of risedronate in reducing fracture risk in agreement with other two trials ${ }^{(24,25)}$ which found a marked reduction in fracture risk using risedronate. Reginster et.al. found that risedronate minimized the risk of fractures in women with osteoporosis ${ }^{(26)}$ and according to Watt's study the fracture risk remained reduced after discontinuation of therapy ${ }^{(27)}$.

Controversy regarding the duration of treatment, a one year duration appears to be effective in our study, however other studies demonstrated a significant BMD improvement after longer duration ${ }^{(28,29)}$

In agreement with current study which revealed minimal upper gastrointestinal side effects, a clinical trial demonstrated that side effects of this drug was not different from those without treatment ${ }^{(27,29)}$, so that we favor the use of this drug to prevent the morbidities associated with accelerated bone loss.

\section{Conclusion and recommendations:}

The bone mineral density results were significantly better in those who received risedronate than those not received the drug. We recommend the routine use of osteoporosis preventive medications in premenopausal women post-hysterectomy to minimize the morbidity of this health problem.

\section{References:}

1. Nick Panay, Menopause and the Postmenopausal Woman. D keith Edmonds, Dewhurst's Textbook of Obstetrics \& Gynaecology. Eighth Edition 2012;554.

2. Calleja-Agius J, Muscat-Baron Y, Brincat MP. Estrogens and the intevertebral disc. Menopause Int 2009;15:127-130.

3. Office of the Surgeon General. Bone Health and Osteoporosis: A Report of the Surgeon General. Rockville (MD): Office of the Surgeon General (US); 2004. Available from: http://www.ncbi.nlm.nih.gov.

4. National Committee for Quality Assurance. Osteoporosis Management in Women Who Had a Fracture. Washington, DC. Available at www.ncqa.org/HEDIS QualityMeasurement.aspx. March 2, 2014.

5. Read MD, Edey KA, Hapeshi J, Foy C. The age of ovarian failure following premenopausal hysterectomy with ovarian conservation. Menopause Int. 2010 Jun;16(2):56-9. 
6. Moorman PG, Myers ER, Schildkraut JM. Effect of hysterectomy with ovarian preservation on ovarian function. Obstet Gynecol 2011 Dec;118(6):1271-9.

7. Farquhar CM, Sadler L, Harvey SA, Stewart AW. The association of hysterectomy and menopause: a prospective cohort study. BJOG. 2005 Jul;112(7):956-2.

8. Actonel [package insert]. Cincinnati, $\mathrm{OH}$ : Procter \& Gamble Pharmaceuticals, Inc., 2010.

9. Watts NB, Diab DL. Long-term use of bisphosphonates in osteoporosis. J Clin Endocrinol Metab. 2010;95:1555-1565.

10. Black DM, Bauer DC, Schwartz AV, Cummings SR, Rosen CJ. Continuing bisphosphonate treatment for osteoporosis,for whom and for how long? N Engl J Med. 2012;366(22):2051-2053.

11. Wallach $S^{1}$, Cohen $S$, Reid DM, et al, Effects of risedronate treatment on bone density and vertebral fracture in patients on corticosteroid therapy. Pubmed.

12. Brown JP, Kendler, DL, McClung MR et al. The efficacy and tolerability of risedronate once a week for the treatment of postmenopausal osteoporosis. Calcif Tissue Int 2002; 2; 103- 11

13. Kanis JA, Melton LJ III, Christiansen C, Johnston CC,Khaltaev N. The diagnosis of osteoporosis. J Bone MinerRes. 1994;9:1137-1141.

14. NIH Consensus Development Panel on Osteoporosis Prevention, Diagnosis, and Therapy. Osteoporosis prevention, diagnosis, and therapy. JAMA. 2001;285:785-795

15. Whiteman MK, Hillis SD, Jamieson DJ, Morrow B, Podgornik MN, Brett KM, et al. Inpatient hysterectomy surveillance in the United States. Am J Obstet Gynecol. Jan; 2008 198(1):34.

16. Singha A, Saha S, Bhattacharjee R, Mondal S, Choudhuri S, Das SK et.al Deterioration of ovarian function after total abdominal hysterectomy with preservation of ovaries. Endocr Pract.2016 Dec;22(12):1387-1392.

17. Ishii K, Aoki Y, Takakuwa K, Tanaka K. Ovarian function after radical hysterectomy with ovarian preservation for cervical cancer. J Reprod Med. 2001 Apr;46(4):347-52.

18. Rud B, Hilden J, Hyldstrup L, Hróbjartsson A. Performance of the Osteoporosis Self-Assessment
Tool in ruling out low bone mineral density in postmenopausal

women: a systematic review. Osteoporos Int. 2007;18:1307.

19. Kanis JA, Oden A, Johnell O, et al. The use of clinical risk factors enhances the performance of BMD in the prediction of hip and osteoporotic fractures in men and women. Osteoporos Int. 2007;18:1033-1046.

20. AACE Postmenopausal osteoporosis guidelines, Endocr. Pract. 2010;16

21. Lanza FL, Hunt RH, Thomson AB, Provenza JM, Blank MA. Endoscopic comparison of esophageal and gastroduodenal effects of risedronate and alendronate in postmenopausal women. Gastroenterology 2000; 119: 631-8.

22. Ebeling P, Roberts A, D'Emden M et al. Risedronate prevents bone loss in early postmenopausal women. J Bone Miner Res 1999; 14:403.

23. Mortensen L, Charles P, Bekker PJ, Digennaro J, Johnston CC Jr. Risedronate increases bone mass in an early postmenopausal population: two years of treatment plus one year of follow-up. J Clin Endocrinol Metab 1998; 83: 396-402.

24. Harris ST, Watts NB, Genant HK et al. Effects of risedronate treatment on vertebral and nonvertebral fractures in women with postmenopausal osteoporosis: a randomized controlled trial. 1999; 282: 1344-52.

25. Reginster JY, Minne HW, Sorensen $\mathrm{OH}$ et al. Randomized trial of the effects of risedronate on vertebral fractures in women with established postmenopausal osteoporosis. Osteoporos Int 2000; 11: 83-91.

26. McClung MR, Geusens P, Miller PD, et al. Effect of risedronate on the risk of hip fracture in elderly women. N Engl JMed. 2001;344:333-340.

27. Watts NB, Chines A, Olszynski WP, et al. Fracture risk remains reduced one year after discontinuation of risedronate. Osteoporos Int. 2008;19:365-372.

28. Sorensen $\mathrm{OH}$, Crawford $\mathrm{GM}$, Mulder $\mathrm{H}$, et al. Long term efficacy of risedronate: a 5-year placebocontrolled clinical experience. Bone. 2003;32:120 126.

29. Mellström DD, Sörensen $\mathrm{OH}$, Goemaere S, Roux C, Johnson TD, Chines AA. Seven years of treatment with risedronate in women with postmenopausal osteoporosis. Calcif Tissue Int. 2004;75:462-468. 